\title{
Correction to: Elevation-specific responses of phenology in evergreen oaks from their low-dry to their extreme high-cold range limits in the SE Himalaya
}

\author{
Song-Wei Wang ${ }^{1,3} \cdot$ Xiao-Fang He $^{1,2} \cdot$ Jian-Guo Chen ${ }^{1} \cdot$ Hang Sun $^{1} \cdot$ Christian Körner $^{3} \cdot$ Yang Yang $^{1}$ (I)
}

Published online: 15 April 2021

(c) Swiss Botanical Society 2021

\section{Correction to: Alpine Botany \\ https://doi.org/10.1007/s00035-020-00245-4}

In the Original publication of the article, the funding number was incorrectly published. The correct funding number should read as 'NSFC-Yunnan joint fund to support key projects is (U1802232). This has been corrected in this paper.

Publisher's Note Springer Nature remains neutral with regard to jurisdictional claims in published maps and institutional affiliations.

The original article can be found online at https://doi.org/10.1007/ s00035-020-00245-4.

Hang Sun

sunhang@mail.kib.ac.cn

$\triangle$ Christian Körner

ch.koerner@unibas.ch

$\triangle$ Yang Yang

yangyang@mail.kib.ac.cn

1 Key Laboratory for Plant Diversity and Biogeography of East Asia, Kunming Institute of Botany, Chinese Academy of Sciences, Kunming, Yunnan, China

2 University of Chinese Academy of Sciences, Beijing, China

3 Institute of Botany, University of Basel, Schönbeinstrasse 6, 4056 Basel, Switzerland 